\title{
Observation of GFP Expression in Pomegranate (Punica granatum L.) Via Pollen-Mediated Transformation
}

\author{
L. Y. Yang ${ }^{1}$, X. Y. Guo ${ }^{1}$, Y. Q. Di ${ }^{1}$, Y. $\operatorname{Sun}^{2,3, *}$ \\ ${ }^{1}$ Department Life Science, Shanxi Normal University, Linfen, P.R. China \\ ${ }^{2}$ The Biotechnology Research Centre, Shanxi Academy of Agricultural Sciences, Taiyuan, P.R. China \\ ${ }^{3}$ Key Laboratory of Crop Gene Resources and Germplasm Enhancement on Loess Plateau, Ministry of Agriculture, Taiyuan, P.R. China
}

Email address:

sunyi692003@163.com(Y.Sun)

*Corresponding author

\section{To cite this article:}

L. Y. Yang, X. Y. Guo, Y. Q. Di, Y. Sun. Observation of GFP Expression in Pomegranate (Punica granatum L.) Via Pollen-Mediated Transformation. Plant. Vol. 4, No. 4, 2016, pp. 23-28. doi: 10.11648/j.plant.20160404.11

Received: August 25, 2016; Accepted: September 5, 2016; Published: September 22, 2016

\begin{abstract}
Pomegranate (Punica granatum L.) is an important fruit crop in the world. Genetic transformation studies of pomegranate have been hindered due to lacking efficient plant regeneration system. At the present study, we explored pollen-mediated transformation for pomegranate where the plasmid DNA harboring GFP was introduced into pollen grains with the aid of sonication. Various sonic parameters showed different effects on pollen grains where the order of effect is ultrasonic intensity $>$ processing duration $>$ treatment times. The observation of GFP in pollen tubes provided the base for potential application of pollen-mediated transformation in pomegranate, which could avoid the tedious tissue culture procedures and easy to apply. And most of all we have provided a novel and efficient approach for pomegranate genetic transformation.
\end{abstract}

Keywords: GFP, Pomegranate, Pollen-Mediated Transformation

\section{Introduction}

Pomegranate (Punica granatum L.) is considered native to Iran [1] and is an economically important fruit tree of the tropical and subtropical regions of the world. It is valued for its pharmaceutical properties and ornamental usage [2], and is one of the richest natural sources of vitamin $\mathrm{C}$ and a good resource of calcium, phosphorus, iron and pectin. It has been well demonstrated that pomegranate fruits, leaves, roots and bark can be used in medicines to treat gastroenteritis, diarrhoea, dysentery and diabetes [3-5]. Meanwhile pomegranate has a great antioxidant potential due to high levels of flavonoids, anthocyanins, tannins, ascorbic acids, and gallic acid presented in the fruit [6]. There is an increasing demand for pomegranate fruits to meet the needs of international markets [7]. However, pomegranate is vulnerable to the attack of insects, which could severely degrade the quality of pomegranate fruits. It is documented that fruit borer (Virachola isocrates) could cause two-fifth loss to the fruit production [8]. Genetic improvement of pomegranate by conventional breeding is a difficult and time consuming process due to long juvenile period, self incompatibility and heterozygous nature [9]. Additionally, conventional breeding has met with limited success due to the lack of some desirable genes in germplasm. Currently, there is few efficient way to reduce the fruit borer attack in pomegranate. Genetic engineering offers a promising way to combat the insect invasion for the effective and available genes from other organisms [10] which has been employed to develop fruit crops with improved horticultural traits such as disease resistance, pest resistance, herbicide tolerance, cold tolerance, salt tolerance, and improved shelf life, etc [11]. The most common approaches are Agrobacterium-mediated transformation and particle bombardment where tissue culture processes are required.

During the past decade, tissue culture techniques have been widely used for the propagation of some important tropical and subtropical fruit trees [12-15]. It has enabled mass propagation of superior genotypes of both wild and cultivated varieties. Rapid clonal propagation has been documented in pomegranate from shoot tip [16], nodal segments and cotyledonary nodes [17], somatic 
embryogenesis [18, 19], shoot organogenesis [20] or leaf segment [21]. Adventitious shoot regeneration has also been reported from cotyledon explant in Punica granatum cv. Ganesh [22] and wild pomegranate [23, 24]. However, several problems, such as exudation of phenolics and browning of media and explants, microbial contamination and recalcitrant in vitro tissues, are associated with in vitro culture of explants. Pomegranate is a difficult species if not a recalcitrant one [25] for propagation. So it is desirable to develop a quick and simple transformation approach that circumvents tissue culture process.

Wang et al. [26] reported transgenic maize plants were obtained by pollen-mediated transformation, then the transgenic sorghum and rape [27]. In above studies, pollen grains were the target for introduction of foreign genes with the help of sonication, followed by pollination of stigmas with transformed pollen grains and subsequent selection of genetically transformed seeds and plants. Pollen mediated-transformation is a quick and easy alternative method to develop transgenic plants, bypassing the requisite for in vitro culture. It has the potential to produce genetically modified plants within a short period, leading to inclusion of the method in crop breeding programs [28].

At the present study, we investigated the sonication effects on pomegranate pollen and explored the feasibility of genetic transformation via pollen-mediated transformation approach where GFP gene was introduced into the pollen grains and the expression of the GFP was observed.

\section{Materials and Methods}

\subsection{Plant Materials}

Pomegranate trees are cultivated on the campus of Shanxi Normal University, and pollen grains were collected from the trees. The plasmid harboring EGFP gene (Figure 1) was kindly provided by Dr. Kan Wang, Plant Transformation Center, Iowa State University, USA.

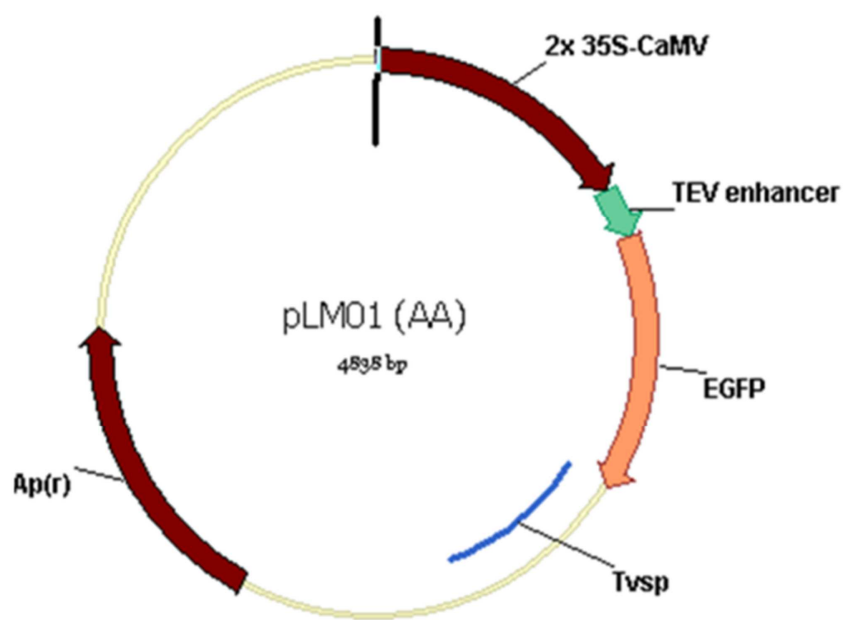

Figure 1. Map of pLM01. The EGFP gene with $2 \times$ CaMV $35 S$ promoter (35S) and a tobacco etch virus 5' untranslated region (TEV) and a soybean vegetative storage protein terminator (Tvsp); Ampicillin (Apr)—resistant marker gene for bacterial selection.

\subsection{Plasmid DNA Preparation}

Plasmid DNA was extracted with alkaline lysis according to Sambrook et al. [29].

\subsection{The Pollen Collection}

Pomegranate flowers were bagged prior to the collection. On collection day, fresh pollen was collected into a paper bag between 8:00-10:00 in mid-May by shaking the flowers, which were either used immediately for downstream treatments or kept in $4^{\circ} \mathrm{C}$ until required.

\subsection{Sonication Treatment Design}

Sonication treatment was performed with an ultrasonic homogenizer (BILON-650Y, Shanghai, China) by submerging the probe of the homogenizer into the pollen suspension. To better understand the effects of sonication parameters on pollen vitality, an orthogonal design was performed with DPS software (Table 1). The factors were: processing intensity (X1), processing durations (X2) and treatment times $(\mathrm{X} 3)$.

Table 1. Orthogonal design for ultrasonic parameters.

\begin{tabular}{lllll}
\hline $\begin{array}{l}\text { Serial } \\
\text { No. }\end{array}$ & $\begin{array}{l}\text { Ultrasonic } \\
\text { intensity (W) }\end{array}$ & $\begin{array}{l}\text { Processing } \\
\text { duration (s) }\end{array}$ & $\begin{array}{l}\text { blank } \\
\text { space }\end{array}$ & $\begin{array}{l}\text { Treatment } \\
\text { times }\end{array}$ \\
\hline 1 & 150 & 5 & 1 & 7 \\
2 & 150 & 7 & 2 & 8 \\
3 & 150 & 9 & 3 & 9 \\
4 & 200 & 5 & 2 & 9 \\
5 & 200 & 7 & 3 & 7 \\
6 & 200 & 9 & 1 & 8 \\
7 & 250 & 5 & 3 & 8 \\
8 & 250 & 7 & 1 & 9 \\
9 & 250 & 9 & 2 & 7 \\
ck & 0 & 0 & & 0 \\
\hline
\end{tabular}

\subsection{Transformation Procedure}

About $0.2 \mathrm{~g}$ pollen was suspended in $20 \mathrm{ml}$ pollen suspension solution ( $5 \%$ sucrose and $500 \mathrm{mgL}^{-1} \mathrm{H}_{3} \mathrm{BO}_{3}$ ) in a beaker, and then treated with an ultrasonic homogenizer. All the sonication procedures were performed on ice to maintain pollen vitality and DNA integrity. Ten $\mu \mathrm{g}$ of the plasmid DNA was added to the treated pollen suspension and sonicated again as described above. Untreated pollen mixed with plasmid DNA in the sucrose solution was used as control. The pollen from 2 groups was inoculated in a shaker, at $25^{\circ} \mathrm{C}$ and $75 \mathrm{rpm}$ for later observation.

\subsection{Pollen Vitality Analysis}

The rates of germination and broken pomegranate pollen was recorded., Three replications per treatment with 100 pollen grains for each were taken The germination rate and the broken rate were counted as following:

pollen germination rate $=($ No. of germinated pollen grains No. of total observed pollen grains) $\times 100 \%$;

pollen broken rate $=($ No. of broken pollen grains/ No. of total observed pollen grains) $\times 100 \%$. 


\subsection{GFP Observation}

GFP expression was observed under a fluorescence microscope (FU-LH100HG, OLMPUS) at $0.5 \mathrm{~h}$ interval with blue light $(495 \mathrm{~nm})$ as the exciting light.

\section{Results and Discussion}

\subsection{The Effects of Sonication Treatment on Pollen Survival}

Pollen germination rate and broken rate under varied ultrasonic parameters were recorded in Table 2. Ultrasonic intensity showed significant effects on pollen germination rate $(\mathrm{p}<0.05)$ (Table 3$)$; all the sonication parameters presented statistical effects on pollen broken rate $(\mathrm{P}<0.05)$ among which the order was ultrasonic intensity $>$ processing durations $>$ treatment times (Table 4 and Table 5). The results showed that compared with the control group, sonication treatment decreased the germination rate and increased broken rate. Among all sonication treatment groups, germination rate in group 1 was the highest, the broken rate was the lowest where the germination rate was $159.7 \%$ higher than group 9 and the broken rate was $65.58 \%$ lower than group 8 . The quadratic polynomial regression analysis on germination rate and broken rate was as following:

The effects of sonication treatment on pollen survival:

Germination rate $(\%)=28.2391-4.1368 X 1-2.5693$ X3$0.8426 \mathrm{X} 2 * \mathrm{X} 2+0.7930 \mathrm{X} 2 * \mathrm{X} 3$;

Broken rate $(\%)=5.8425+15.6384 \mathrm{X} 1+1.7768 \mathrm{X} 2 * \mathrm{X} 3$

Table 2. The results of orthogonal experiment.

\begin{tabular}{lllll}
\hline \multirow{2}{*}{ No. } & Germination Mean & Significance & Broken Mean & Significance \\
\cline { 2 - 5 } & rate(\%) & (Sig). & rate(\%) & (Sig). \\
\hline 1 & 21.92 & $\mathrm{a}$ & 21.23 & $\mathrm{i}$ \\
2 & 19.04 & $\mathrm{ab}$ & 30.60 & $\mathrm{~h}$ \\
3 & 15.74 & $\mathrm{bc}$ & 36.19 & $\mathrm{~g}$ \\
4 & 14.93 & $\mathrm{bc}$ & 43.59 & $\mathrm{e}$ \\
5 & 13.67 & $\mathrm{~cd}$ & 40.14 & $\mathrm{f}$ \\
6 & 11.80 & $\mathrm{cde}$ & 49.77 & $\mathrm{~d}$ \\
7 & 11.08 & $\mathrm{cde}$ & 56.00 & $\mathrm{c}$ \\
8 & 9.98 & $\mathrm{de}$ & 61.69 & $\mathrm{a}$ \\
9 & 8.44 & $\mathrm{e}$ & 58.83 & $\mathrm{~b}$ \\
$\mathrm{Ck}$ & 61.92 & & 6.23 & \\
\hline
\end{tabular}

Note: Different letters denote significant difference at $5 \%$ level

Table 3. Variance analysis of orthogonal test effect on germination rate.

\begin{tabular}{|c|c|c|c|c|c|}
\hline Sources & Sum of squares( SS) & Degrees of freedom (Df) & The mean square (MS) & The F value (F) & Significance (Sig) \\
\hline Ultrasonic intensity(W) & 124.9267 & 2 & 62.4633 & 105.4233 & 0.009 \\
\hline Interval time (S) & 20.5773 & 2 & 10.2886 & 17.3648 & 0.055 \\
\hline Treatment times & 5.8409 & 2 & 2.9204 & 4.9290 & 0.169 \\
\hline Error & 1.185 & 2 & 0.5925 & & \\
\hline Total & 152.5298 & 8 & & & \\
\hline
\end{tabular}

Note: Different letters denote significant difference at 5\% level.

Table 4. Variance analysis of the factors on broken rate.

\begin{tabular}{|c|c|c|c|c|c|}
\hline Sources & Sum of squares( SS) & Degrees of freedom(Df) & Degrees of freedom(Df) & The $F$ value (F) & Significance (Sig.) \\
\hline Ultrasonic intensity (W) & 1305.7112 & 2 & 652.8556 & 16444.7254 & $<0.001$ \\
\hline Interval time (S) & 95.7914 & 2 & 47.8957 & 1206.4408 & $<0.001$ \\
\hline Treatment times & 82.2102 & 2 & 41.1051 & 1035.3930 & $<0.001$ \\
\hline Error & 0.0794 & 2 & 0.0397 & & \\
\hline Total & 1483.7922 & 8 & & & \\
\hline
\end{tabular}

Note: Different letters denote significant difference at 5\% level.

Table 5. Different levels of various factors on pollen germination rate and broken rate.

\begin{tabular}{llll}
\hline & & Germination rate (\%) & Broken rate (\%) \\
\hline \multirow{3}{*}{ Ultrasonic power (W) } & 150 & $18.900 \mathrm{a}$ & $29.340 \mathrm{c}$ \\
& 200 & $13.467 \mathrm{~b}$ & $44.500 \mathrm{~b}$ \\
& 250 & $9.833 \mathrm{c}$ & $58.840 \mathrm{a}$ \\
Processing duration (s) & 5 & $15.557 \mathrm{a}$ & $40.273 \mathrm{c}$ \\
& 7 & $14.650 \mathrm{ab}$ & $44.143 \mathrm{~b}$ \\
Treatment times & 9 & $11.993 \mathrm{~b}$ & $48.263 \mathrm{a}$ \\
& 7 & $15.097 \mathrm{a}$ & $40.067 \mathrm{c}$ \\
& 9 & $13.973 \mathrm{a}$ & $45.457 \mathrm{~b}$ \\
\end{tabular}

Note: Different letters denote significant difference at $5 \%$ level. 


\subsection{Pollen Grain Observation}

Based on orthogonal experiment results, the power of the ultrasonic homogenizer was set to $150 \mathrm{w}$ and the sonication treatment lasted for $5 \mathrm{~s}$ each time with an interval of $10 \mathrm{~s}$ for a total of 7 times. Under blue exciting light, the green fluorescence
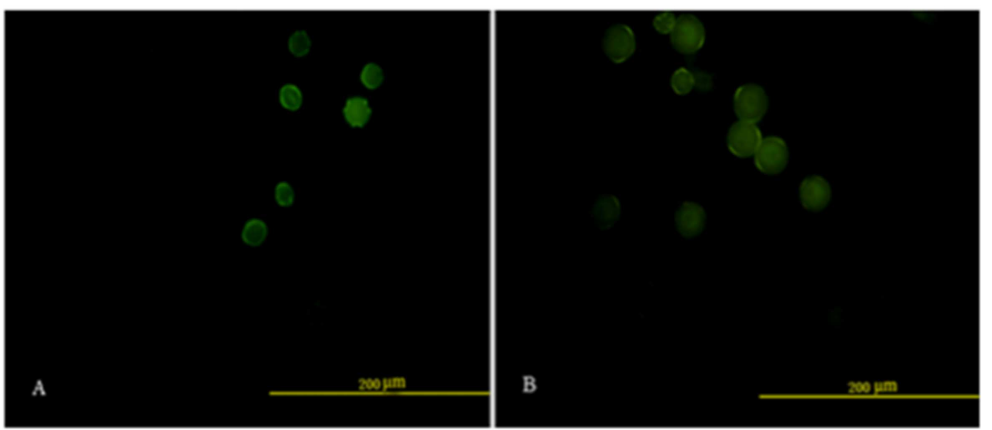

Figure 2. The images of pomegranate pollen grains. A: The images of treated pomegranate pollen grains under blue light; B: The images of control pollen grains under blue light. The pictures were taken with the same exposure time.

\subsection{Pollen Tube Observation}

Under blue (Fig. 3A') light, the pollen tubes in control group could not be observed though they are visible under white light (Fig. 3B'). However, in the treatment group, strong green fluorescence presented from some pollen tubes under blue light (Fig. 3A ) and all the tubes can be observed was observed from both the treatment and control groups, and no visible difference presented. The control group produced the same result, which implied that it is hard to identify the transformed pollen by solely observing pollen grains.
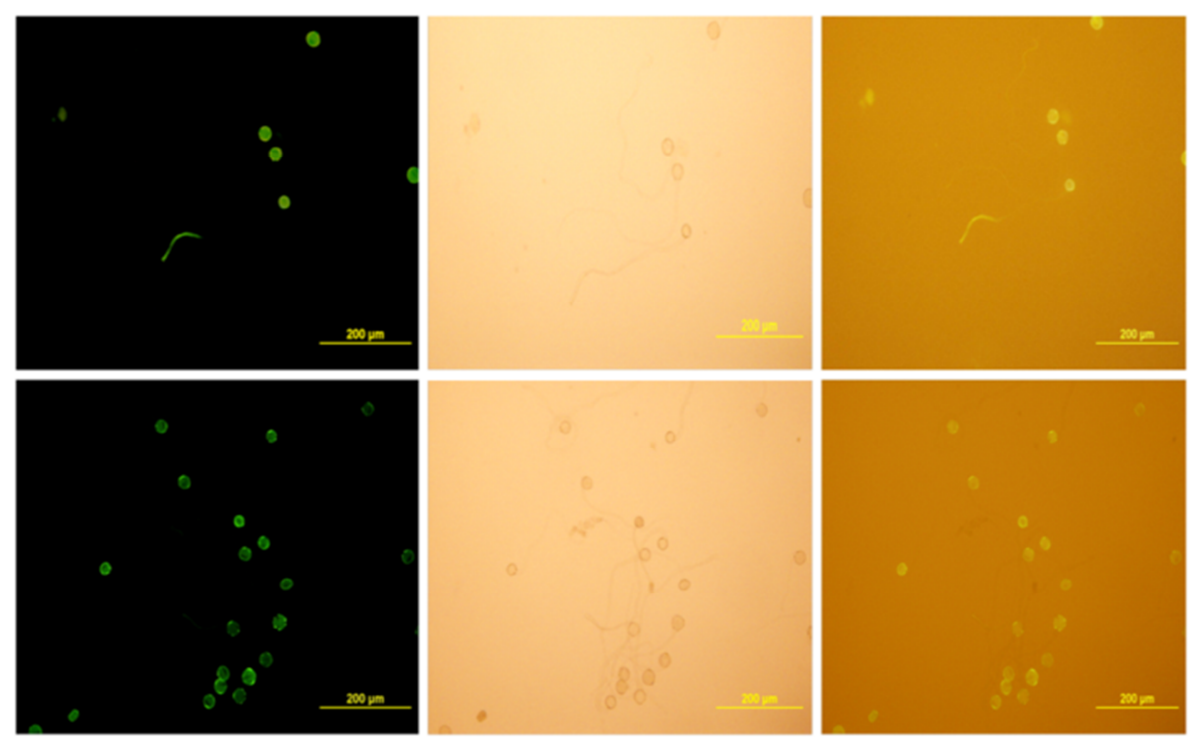

Figure 3. The expression of GFP in pollen tube of pomegranate. A, B, C: Image of pollen tubes from the treatment group under blue, white and overlapping lights, respectively; A', B', C': Image of pollen tube from control group under blue, white and overlapping lights, respectively. The corresponding pictures were taken with the same exposure time.

\section{Conclusions}

Pomegranate pollen grains have 3 pores, so it is possible for plasmid DNA to be transferred into the pollen through pores with the aid of sonication. Pollen grain is an ideal target for transformation, since they are produced in large numbers, which can be easily collected from anthers and transgenic genes can be introduced directly in the form of naked DNA or through mediation of Agrobacterium [28]. Booy et al. [30] reported that the digestion of plasmid DNA by nuclease was a major hurdle for using pollen as a genetic transformation vector.

Wang et al. [26] showed that the sonication treatment with certain intensity could inactivate the nuclease and allow exotic DNA to be transferred into a recipient genome through pollination. After pollen grains were treated with sonication, 
quite a few pollen grains were broken, and the ultrasonic intensity, processing duration and treatment times showed the significant effects, among which ultrasonic intensity is the most important factor that influences the pollen vitality, followed by interval times and treatment times. GFP was observed in the pollen tubes in the treatment group, which confirmed the feasibility of pollen-mediated transformation for pomegranate. We also observed the green auto-fluorescent of pollen grains was strong under blue light and therefore can't identify the GFP pollen; some other gene as YFP or RFP might apply in the future study. Though we are not able to obtain the transgenic seeds due to the tree ownership, we would suggest the novel pollen-mediated transformation approach be applied for pomegranate genetic transformation, which circumvents the plant tissue culture procedures.

\section{Acknowledgements}

This research project was supported by the Fund Program for the Scientific Activities of Selected Returned Overseas Professionals in Shanxi Province (2014-95) and Undergraduate Science and Technology Innovation Project of Shanxi Normal University (SD2014CXXM-18).

\section{References}

[1] E. Stover, E. W. Mercure, The pomegranate: a new look at the fruit of paradise. Sci Hortic. vol. 42, 2007, pp. 1088-1092.

[2] M. T. Jurenka, Therapeutic applications of pomegranate (Punica granatum L.): a review. Alternat Med Rev. vol. 13, 2008, pp. 128- 144.

[3] V. S. Jaiswal and M. N. Amin, Guava and jackfruit. In: Hammerschlag F. A., Litz R. E. (eds), Biotechnology of perennial fruit crops, Biotechnology in agriculture. Vol. 8. CAB International, Wallingford,UK, 1992, pp. 421-431.

[4] M. K. Rai, V. S. Jaiswal and U. Jaiswal, Alginate-encapsulation of nodal segments of guava (Psidium guajava L.) for germplasm exchange and distri-bution. J. HORT. SCI. BIOTECH. Vol. 83, 2008, pp. 569-573.

[5] A. Saxena, and N. K. Vikram, Role of selected Indian plants in management of type 2 diabetes: a review. J. Altern. Complement Med. Vol. 10, 2004, pp. 369-378.

[6] J. M. Salgado, T. R. B. Ferreira, F. D. Biazatto and C. T. S. Dias, Increased Antioxidant Content in Juice Enriched with Dried Extract of Pomegranate (Punica granatum) Peel.

[7] R. Deepika and K. Kanwar, In vitro regeneration of Punica granatum L. plants from different juvenile explants. J. Fruit Ornamental Plant Res. Vol. 18, 2010, pp. 5-22.

[8] K. L. Kakar, G. S. Dogra and A. Nath, Incidence and control of pomegranate fruit borers, Virachola isocrates Fb. and Deudorix epijarbas Moore. Indian J. Agr. Sci. Vol. 57, 1987, pp. 749-752.

[9] S. H. Jalikop, Pomegranate Breeding. Fruit, Vegetable and Cereal Sci. Biothec. Vol. 4, 2010, pp. 26-34.
[10] Vipasha Verma, Kamlesh, Kanwar, Mahak, Tufchi, and Monika Kashyap. Agrobacterium- Mediated CrylA Gene Transfer in Punica granatum L. cv. Kandhari Kabuli Using Different In Vitro Regeneration Pathways. J. Crop Sci. Biotech. Vol. 17, No. 1, pp. 1-10, March 2014.

[11] M. A. Gomez-Lim and R. E. Litz, Genetic Transformation of Perennial Tropical Fruits. InVitro Cell Dev Biol Plant. Vol. 40, 2004, pp. 442-449.

[12] S. Agarwal, K. Kanwar and D. R. Sharma, Factors affecting secondary somatic embryogenesis and embryo maturation in Morusalba L. Sci Hortic. Vol. 102, 2004, pp. 359-368.

[13] T. Tsukamoto, M. Gao, K. Negoro, H. Hanada, R. Tao, M. Kawabe and K. Yonemori, Somatic embryogenesis and plant regeneration from immature cotyledons of Prunus mume 'Nanko'. Acta Horticult. Vol. 738, 2007, pp. 697-701.

[14] O. Perez-Tornero, C. I. Tallon and I. Porras, An efficient protocol for micropropagation of lemon (Citrus limon) from mature nodal segments. Plant Cell Tissue Organ. Vol. 100, 2010, pp. 263-27.

[15] F. G. Skiada, K. Grigoriadou and E. P. Eleftheriou, Micropropagation of Vitis vinifera L. cv. 'Malagouzia' and 'Xinomavro'. Cent Eur J Biol. Vol. 5, 2010, pp. 839-852.

[16] D. M. Mahishi, A. Muralkrishna, G. Shivashankar and R. S. Kulkarni, Shoot tip culture method for rapid clonal propagation of pomegranate (Punica granatum L.). Horticultural - New Tech and App. 1990, pp. 215-217.

[17] S. K. Naik, S. Pattnaik and P. K. Chand, In vitro propagation of pomegranate (Punica granatum L. cv. Ganesh) through axillary shoot proliferation from nodal segments of mature tree. Sci Hortic. Vol. 79, 1999, pp. 175-183.

[18] R. R. Bhansali, Somatic embryogenesis and regeneration of plant-lets in pomegranate. Ann Bot. Vol. 66, No. 3, 1990, pp. 249-253.

[19] K. Nataraja and G. K. Neelambika, Somatic embryogenesis and plant-let formation from petal cultures of pomegranate (Punica granatum L.). Indian J Exp Biol. Vol. 34, No. 7, 1996, pp. 719-721.

[20] T. Moriguchi, M. Omura, N. Matsuta and I. Kozaki, In vitro adventitious shoot formation form anthers of pomegranate. Hort Sci. Vol. 22, 1987, pp. 947-948.

[21] M. Omura, N. Matsuta, T. Moriguchi, I. Kozaki and T. Sanada, Establishment of tissue culture methods in dwarf pomegranate (Punica granatum L. var. Nana) and application for the induction of variants. Bull Fruit Tree Res Station. Vol. 14, 1987, pp. $17-44$.

[22] S. K. Naik and P. K. Chand, Silver nitrate and aminoethoxy vinylglycine promote in vitro adventitious shoot regeneration of pome-granate (Punica granatum L.). J Plant Physiol. Vol. 160, No. 4, 2003, pp.423-430.

[23] A. A. Murkute, S. Patil, B. N. Patil and M. Kumari, Micropropagation in pomegranate, callus induction and differentiation. South Indian Hortic. Vol. 50, No.1, 3, 2002, pp.49-55.

[24] K. Kanwar, J. Joseph and D. Raj, Comparison of in vitro regeneration pathways in Punica granatum L. Plant Cell Tiss Org Cult. Vol. 100, 2010, pp. 199-207. 
[25] S. K. Naik, and P. K. Chand, Tissue Culture-Mediated Biotechnological Intervention in Pomegranate: a Review. Plant Cell Rep. Vol.30, 2011, pp.707-721.

[26] Wang, Jin-xue., Sun, Yi., Cui, gui-mei., and $\mathrm{Hu}$, Jing-jing.Transgenic Maize Plants Obtained by Pollen mediated Transformation. Actor Botanica Sinica. Vol. 43, No.3, 2001, pp.275-279.

[27] Wang, Wei-quan., Wang, Jing-xue., and Yang, Cui-ping.Pollen-mediated transformation of Sorghum bicolor plants. Biotechnology and Applied Biochemistry. Vol. 48, 2007, pp. 79-83.
[28] S. Eapen, Pollen grains as a target for introduction of foreign genes into plants: an assessment. Physiol Mol Biol Plants. Vol. 17, No. 1, pp. 1-8, March 2011.

[29] J. Sambrook, D. Russell, Molecular cloning: A Laboratory Manual (3nd edition), Science Press: Beijing, 2002.

[30] G. Booy, F. A. Krens and H. J. Huizing, Attempted pollen-mediated transformation of maize. J Plant Physiol. Vol. 135, 1989, pp. 319-324. 